\title{
Kilobecquerel per Microliter
}

National Cancer Institute

\section{Source}

National Cancer Institute. Kilobecquerel per Microliter. NCI Thesaurus. Code C71168.

A metric unit of volumetric radioactivity concentration defined as a concentration of a radionuclide with an activity equal to one thousand becquerels per unit volume equal to one millionth of a liter. 